Article

\title{
Using Satellite and Lightning Data to Track Rapidly Developing Thunderstorms in Data Sparse Regions
}

\author{
Morné Gijben ${ }^{1, *}$ and Estelle de Coning ${ }^{2}$ \\ 1 South African Weather Service, Pretoria 0181, Gauteng, South Africa \\ 2 World Meteorological Organization, Geneva 1211, Switzerland; edeconing@wmo.int \\ * Correspondence: morne.gijben@weathersa.co.za; Tel.: +27-12-367-6146 \\ Academic Editor: Guifu Zhang \\ Received: 10 February 2017; Accepted: 22 March 2017; Published: 20 April 2017
}

\begin{abstract}
Radar systems provide the most useful information about the intensity, movement, and characteristics of severe thunderstorms, but are expensive to maintain and require extensive maintenance. In South Africa, some areas are not covered by radar systems, while very few operational radar systems exist in other southern African countries. Despite these shortcomings, all meteorological centers still have to warn the public of pending severe weather events. The Nowcasting Satellite Application Facility (NWC SAF) in Europe developed software that utilizes satellite data to identify and track rapidly developing thunderstorms (RDT). The NWC software was installed at the South African Weather Service in 2014. Initially, the RDT product was validated against lightning data and the results showed that the RDT product could provide very useful information on possible severe or intense convective storms. This study focusses on the effects of including lightning as an ancillary dataset into the algorithms and then validating the RDT product against radar data. Twenty-five summer cases were considered to determine whether the inclusion of lightning data had a positive effect on the accuracy of the RDT product, when compared to radar data. The results of this study show that in the majority of the cases, the inclusion of lightning data was beneficial to the RDT product. On average the Probability of Detection (POD) improved by $6.6 \%$, the Heidke Skill Score (HSS) by $4.6 \%$, and the False alarm ratio (FAR) by $0.1 \%$. To our knowledge, South Africa is the only African country which is running the NWC SAF software operationally and which has performed an evaluation of the product over Africa against observations from radar systems and lightning sensors. The outcomes of this study are very encouraging for other countries in Africa where convection and severe convection often occur and sophisticated data sources are absent. Initial studies over East Africa indicate that the RDT product can benefit operational practices for the nowcasting of severe convection events.
\end{abstract}

Keywords: satellite; nowcasting; thunderstorms; data sparse regions; radar; lightning

\section{Introduction}

Nowcasting is the science of anticipating the ordinary and severe weather events in the next few hours ( $0-6$ h) [1]. Severe convective weather events can include heavy rainfall, strong winds, hail, and/or tornadoes [2]. Various sectors of society need to be able to prepare for these events in order to prevent loss of life and damage to property. The issuing of weather-related warnings for such events in South Africa is the mandate of the South African Weather Service (SAWS). In an ideal world, radar systems provide the most useful information about the intensity, movement, and characteristics of severe weather events, but these data sources are expensive to obtain and require extensive maintenance. In South Africa, radar systems do not provide coverage of the entire country and this leaves gaps between radar systems. In other southern African countries, very few operational 
radar systems exist. Despite the shortcomings in data resources, all meteorological centers still have to warn the public of pending severe weather events in order to save lives and property.

The geostationary Meteosat Second Generation (MSG) satellite provides data coverage over all African countries every $15 \mathrm{~min}$ and has a nominal (at nadir) resolution of $3 \mathrm{~km}$ for most of the 12 channels. Over South Africa, the resolution of satellite data is between 4 and $5 \mathrm{~km}$ in a north-south direction and between 3 and $4 \mathrm{~km}$ in an east-west direction (depending on the location in South Africa) [3]. The operational use of satellite images and derived products, as a possible tool for nowcasting of severe convective weather events in these data-sparse regions, is increasingly important for these National Meteorological and Hydrological Services (NMHS). Using MSG data, in combination with input from numerical weather prediction (NWP) models, can be an excellent second option for nowcasting purposes in areas that are not covered by radar data or where no radar systems are available [4].

In order to optimize the use of satellite data, different centers-so-called Satellite Application Facilities (SAF) - were established in the European region to develop derived products for different purposes, including nowcasting [5]. The Nowcasting (NWC) SAF developed various products, some of which can be very useful for the nowcasting of severe weather events. One of the products, developed within the NWC SAF framework by Météo-France, is called the "Rapidly Developing Thunderstorms" (RDT) product. The RDT product uses mainly geostationary (MSG) satellite data and provides information on cloud characteristics and phases related to significant convective systems [6]. An objective validation of the RDT product (using the 2011 version of the software) was conducted over Europe from June to August 2008 and April to October 2009 (Northern Hemisphere summer) by the developers. Cloud-to-ground (CG) lightning activity over the European region was used as ground truth. The conclusion of the validation report states: "RDT provides an accurate depiction of convective phenomena, from triggering phase to mature stage. The RDT object allows pointing out some areas of interest of a satellite image. The RDT provides relevant information on triggering and development clouds and on mature systems." [7]. Histories of previous time-steps of the RDT polygons are used together with the latest time-step to estimate the direction in which the storm cell will move in the next few minutes (extrapolation technique). This makes the RDT product useful to identify and nowcast the storms within the next few minutes. The 2013 version of the NWC SAF (used in this study) did not have the capability to provide forecasted tracks of where storms will be in the next 15, 30, 45, and $60 \mathrm{~min}$. This feature was introduced into the 2016 version of the software, which was released at the end of 2016, and will enhance the lead-time of nowcasts made by RDT for up to an hour in advance.

Other satellite-based storm tracking algorithms exist, such as Cb-TRAM (Cumulonimbus Tracking and Monitoring), MASCOTTE (Maximum Spatial Correlation Tracking Technique), and ForTraCC (Forecast and Tracking the Evolution of Cloud Clusters) [8]. The Cb-TRAM algorithm from the German Aerospace Center (DLR), detects, tracks, and nowcasts thunderstorms with data from MSG and is similar to the RDT product. As with the RDT, evaluations of the Cb-TRAM product over Europe and South Africa against lightning data also showed favorable results [9]. A major advantage of RDT compared to Cb-TRAM is that RDT forms part of the NWC SAF software that is freely available on the NWC SAF website, which makes it more accessible to developing countries [10].

In 2013, the 2012 version of the NWC SAF software was installed in South Africa. Improvements are frequently made to the software by the developers and a 2013 version of the software soon followed. This 2013 version of the NWC SAF software was installed and made operational in South Africa during 2014. For the southern African region, the software uses the local version of the United Kingdom Meteorological Office (UKMO) Unified Model (UM). The version of the UM used in this study was available once a day, using a $12 \mathrm{~km}$ horizontal resolution and 38 vertical levels. The UM has an hourly output for up to $48 \mathrm{~h}$ ahead [11]. Satellite data from the MSG are readily available every $15 \mathrm{~min}$. Aside from using MSG (mandatory) and UM (optional) data, the RDT product can be used with an auxiliary lightning dataset. Initial tests were done to validate the RDT objects (without using lightning data 
as input) against the occurrence of lightning objects over South Africa [12]. The results were very encouraging and showed that the RDT product can be very useful for the identification and tracking of the more intense parts of thunderstorms using MSG and NWP data.

The developers of the RDT product recommend that lightning data should, if possible, be used as input data into the software to characterize electrical activity of convective systems in order to force the identification of convective systems. The South African Lightning Detection Network (SALDN) consists of 25 Vaisala LS 7000 and 7001 sensors across the country and detects lightning with a theoretical detection efficiency of $90 \%$ and location accuracy of $500 \mathrm{~m}$. These sensors detect mostly CG lightning and thus do not capture most of the intra-cloud (IC) lightning or cloud-to-cloud (CC) lightning [13]. During the developing phase of a thunderstorm predominantly IC lightning is found, while in the mature phase of a storm most of the CG and IC lightning occur [14].

The aim of this work was to test the effect of including lightning data as auxiliary dataset into the RDT product. This was achieved by verifying the RDT (with and without lightning data added as input data) to the software algorithms against radar reflectivity over South Africa. The results of twenty-five case studies over the South African domain showed that the RDT product already provides favorable results when lightning data is omitted from the software and that the inclusion of lightning data further enhances the performance of the product. In regions not covered by radar systems, the RDT could provide additional information on possible severe or intense storms and can have many applications, such as for the aviation industry in assisting with the navigation of air traffic around the intense thunderstorms.

\section{Materials and Methods}

A detailed description of the RDT software can be found in the NWC SAF documentation [6]. The RDT product (together with other NWC SAF products that feed into the RDT) requires the use of eleven of the twelve channels from the MSG satellite. This includes: High Resolution Visible, Visible (VIS) 0.6, VIS 0.8, Infrared (IR) 1.6, IR 3.9, Water Vapor (WV) 6.2, WV 7.3, IR 8.7, IR 10.8, IR 12.0, and IR $13.4 \mu \mathrm{m}$. The NWP fields that are needed in the RDT includes: 2 meter $(\mathrm{m})$ temperature, $2 \mathrm{~m}$ relative humidity, $2 \mathrm{~m}$ dew point temperature, surface pressure, temperature and humidity at all the levels of the NWP, temperature of the tropopause, geopotential at the surface, as well as a land sea mask [15]. The local version of the UM used for the case studies was available once a day at a horizontal resolution of $12 \mathrm{~km}$, with hourly output for $48 \mathrm{~h}$ ahead.

Similar to the satellite data, the RDT product updates every $15 \mathrm{~min}$ and is available during day and nighttime. The RDT algorithm consists of three parts, namely, the detection, tracking, and discrimination of cloud systems. During the detection of cells, the RDT algorithm uses an adaptive threshold deduced from the brightness temperature patterns of each cell and its surroundings (from the IR 10.8 satellite channel) [6]. The tracking algorithm uses the speed and movement of cells between two consecutive time steps to track a cell based on the principle of overlapping. Characteristics of the cells between two time steps, such as volume and cooling rate, are used as input into the discrimination algorithm [6]. The discrimination algorithm identifies the convective elements from all cloud cells by using statistical and empirical rules tuned on a learning database. Five MSG channels (IR 10.8, IR 8.7, IR 12.0, WV 7.3, and WV 6.2) together with NWP parameters are used in the discrimination algorithm. The different phases of the storms are determined by using the cell history, cooling or warming of the cells, vertical extent, expansion rate, and whether there is convective activity in the storm (if lightning data are used as input). NWP data are used to identify areas that are stable and where no convective development should occur. The final output provides polygons of the rapidly developing cells that have a phase of growing, mature, or decaying [6,12].

For the purpose of this work, twenty-five cases, listed in Table 1, were used between September and March (southern hemisphere spring/summer) when most convective activity occurs in South Africa. Nine cases from 2011, 2012, and 2013 were selected based on the availability of satellite and model data, as well as the availability of computer resources to process the data. In order to 
cover a more extensive period, sixteen more cases from 15 to 30 March 2015 were added to the dataset. On each of these days, the times between 1100 and 1800 Coordinated Universal Time (UTC) were considered, as this coincides with the time when most heat driven convection in South Africa occurs (i.e., late afternoon and early evening in summer time) [16]. The study focused on the area inside the borders of South Africa covered by radar systems.

Table 1. The 25 case dates considered in the evaluation of the rapidly developing thunderstorms (RDT).

\begin{tabular}{ccccc}
\hline \multicolumn{5}{c}{ Case Dates } \\
\hline 31 December 2011 & 8 November 2012 & 16 March 2015 & 21 March 2015 & 26 March 2015 \\
6 September 2012 & 9 November 2012 & 7 March 2015 & 22 March 2015 & 27 March 2015 \\
9 October 2012 & 10 December 2012 & 18 March 2015 & 23 March 2015 & 28 March 2015 \\
17 October 2012 & 19 January 2013 & 19 March 2015 & 24 March 2015 & 29 March 2015 \\
20 October 2012 & 15 March 2015 & 20 March 2015 & 25 March 2015 & 30 March 2015 \\
\hline
\end{tabular}

Radar data from 11 S-band (operating on a wavelength of 8-15 cm and a frequency of 2-4 GHz) and $3 \mathrm{C}$-band (operating on a wavelength of $4-8 \mathrm{~cm}$ and a frequency of $4-8 \mathrm{GHz}$ ) radars were used as ground truth for validation of the RDT polygons. The radar systems in South Africa are frequently calibrated to ensure that they operate at optimal performance. Unfortunately, radar data are not always available due to a number of reasons. The areas covered by radar across the country varied from day-to-day and even from time to time, during any day. To deal with these variations, the first step was to identify the radar systems which were available (or operational) between 1100 and 1800 UTC of each of the case dates. Figure 1 shows a map of the radar system mosaic over South Africa if all radars were operational (red) and this was taken as the study domain for the evaluation. When radar data were not available, the coverage domain of that radar was removed from the study domain when calculating the evaluation statistics.

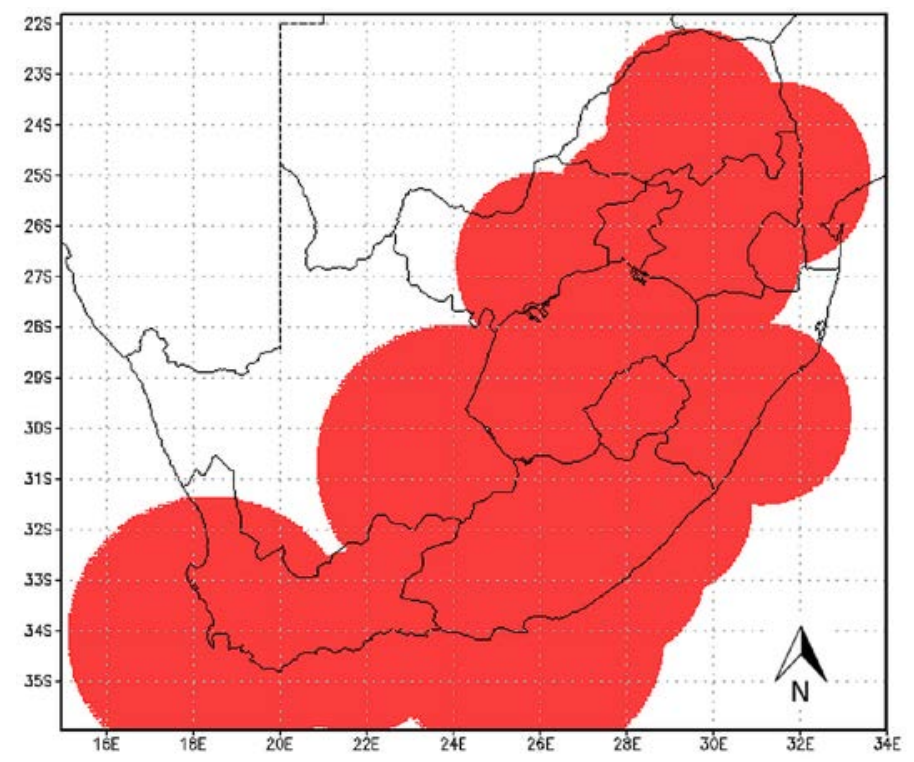

Figure 1. The areas of South Africa covered by radar systems (red) when all radars are operational.

A second challenge when using radar data is that the scanning interval of the radars changed from 5 min intervals to 6 min intervals in 2014. For the older (2011,2012, and 2013) case days, the interval of radar mosaic data was every $5 \mathrm{~min}$, while the intervals of the 2015 cases were every $6 \mathrm{~min}$. The interval of RDT data - which relates to satellite data-on the other hand, is every $15 \mathrm{~min}$. For the cases prior to 2014, the maximum radar reflectivity in the $10 \mathrm{~min}$ before and after the RDT timestamp was used for the evaluation. For the 2015 cases, the 6 min interval radar data does not correspond so well with the 
RDT time stamps. MSG data is available every $15 \mathrm{~min}$ (at 00, 15, 30, and $45 \mathrm{~min}$ ), while the 6 min radar data were available at $00,06,12,18,24,30,36,42,48$, and $54 \mathrm{~min}$ past the hour. As a result, the RDT times of 15 and $45 \mathrm{~min}$ do not correspond easily with radar data times. When the RDT timestamp was 00 or 30 min past the hour, the radar data for the $6 \mathrm{~min}$ following the RDT time were used. When the RDT timestamp was 15 and 45 min past the hour, the radar data for the 6 min surrounding the RDT time ( 3 min before and after RDT) were used.

Lightning data supplied by the SALDN was used as input into the RDT product. To include lightning data into the processing for RDT, two settings are made in the configuration file. On recommendation of the developers: (a) $600 \mathrm{~s}$ (10 $\mathrm{min}$ ) before and after each RDT time step are used as the time window for lightning data to be included in the calculation; (b) three satellite pixels are set as the distance between the satellite cell and the lightning stroke with which it is associated; and (c) 15 or more lightning strokes must be associated with the satellite cell [17]. This means that the calculations of the RDT product considers all lightning strokes that occur in the 10 min before and after the RDT time step, and considers lightning strokes up to a distance of three satellite pixels from the satellite cell in order to take into account lightning outside a cell. Furthermore, at least 15 lightning strokes must be associated with a cell based on the previously mentioned conditions. Evaluation of the RDT product was performed with and without lightning data added to the algorithm to determine if the lightning data adds value to the product.

The RDT algorithm is an object-orientated methodology to identify and track thunderstorms by means of polygons for different phases of the convective storms-triggering, growing, and mature. To validate these objects against radar reflectivity requires an object-orientated methodology, which was also followed by the developers [7]. An overview of the research done on spatial validation methodology is provided by [18]. Object-based approaches identify different attributes (such as position and size) to each individual pair of forecast/observed "objects" [18]. The methodology behind object-orientated methods forms part of the statistical software package called SpatialVx [19] as part of the " $R$ " programming language [20]. Figure 2 shows an example of how the SpatialVx software [19] transforms features of the RDT and radar over the study domain into objects and matches these objects. Figure 2a shows the RDT overlaid on satellite imagery for 9 October 2012 at 1315 UTC. Figure 2b shows how the SpatialVx software transforms these RDT polygons into objects (Figure 2b-right), transforms radar data into objects (Figure 2b-left), and then matches these RDT and radar objects as indicated by the corresponding colors.

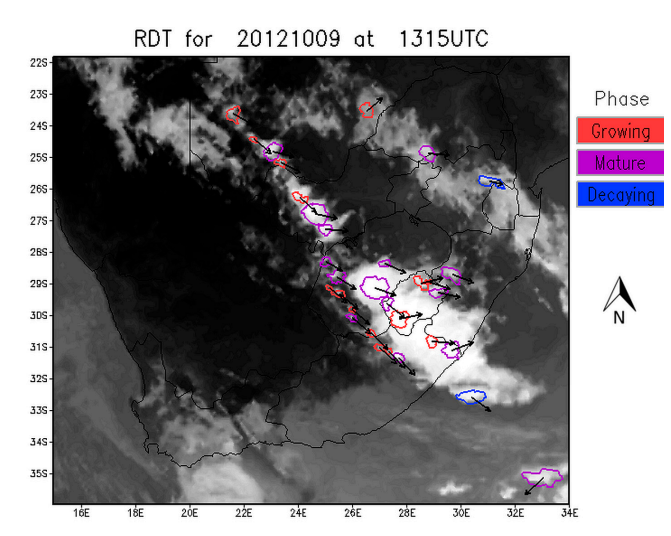

(a)
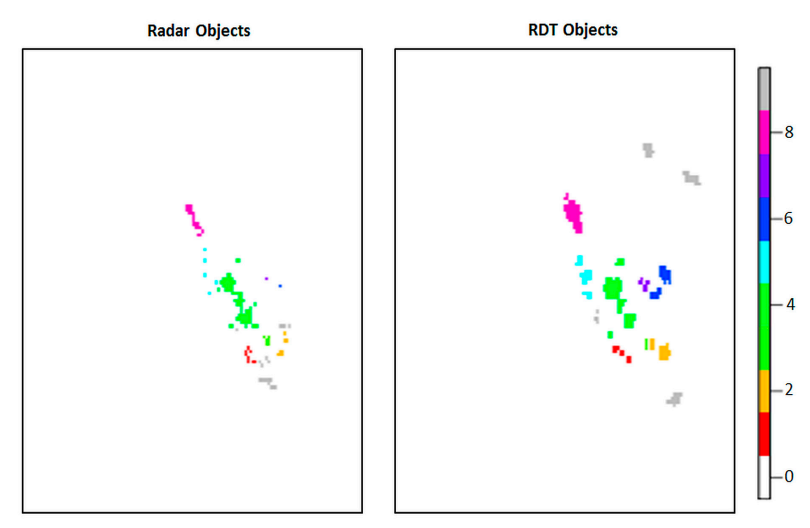

(b)

Figure 2. An example of the rapidly developing thunderstorm (RDT) product overlaid on a satellite image (a) and an object-orientated comparison between radar objects and RDT objects (b) over the study domain. The colors in (b) indicate the matched radar and RDT objects. Grey objects represent false alarms and misses. 
Based on these objects or features, new definitions for hits, misses, and false alarms can be calculated according to the identified objects. Contingency table verification metrics like the probability of detection (POD), probability of false detection (POFD), false alarm ratio (FAR), and Heidke skill score (HSS) could then be calculated from the hits, misses, and false alarms [21]. Table 2 gives the range and perfect score values for the verification metrics used in this study. This software package was used to do an object-orientated validation of the RDT polygons against the radar reflectivity polygons in this study. The standard output statistics calculated by the SpatialVx package, namely the POD, POFD, FAR, and HSS were used in this study. The hits, misses, false alarms, and correct negatives could also be used to calculate other statistical scores, but these were not considered in this paper.

Table 2. Contingency table scores used to evaluate the rapidly developing thunderstorms (RDT) against radar. POD, probability of detection; POFD, probability of false detection; FAR, false alarm ratio; HSS, Heidke skill score.

\begin{tabular}{ccc}
\hline Score & Range & Perfect Score \\
\hline POD & 0 to 1 & 1 \\
POFD & 0 to 1 & 0 \\
FAR & 0 to 1 & 0 \\
HSS & -1 to 1 & 1 \\
\hline
\end{tabular}

When radar data are considered, $35 \mathrm{dBZ}$ is usually seen as a threshold to start tracking thunderstorms. A reflectivity value of $<30 \mathrm{dBZ}$ indicates light rain, $30-40 \mathrm{dBZ}$ indicates light to moderate rain, 40-50 dBZ indicates moderate to heavy rain, and $>50 \mathrm{dBZ}$ heavy rain. At reflectivity values above $50 \mathrm{dBZ}$, hail is likely [22]. Using an object approach, cell-tracking algorithms define such an object as an area where the reflectivity exceeds a threshold $-35,40$, and $45 \mathrm{dBZ}$ are most typically used [23,24]. In order to consider all the phases of the storms in the evaluation of the RDT product, radar reflectivity greater and equal to $35 \mathrm{dBZ}$ were used, to exclude less significant storms and align with the RDT principle of rapidly developing and/or intense parts of thunderstorms. The threshold of $35 \mathrm{dBZ}$ was also used and recommended in the validation of the RDT by Météo-France: " $35 \mathrm{dBZ}$ is the first threshold we use to follow radar-detected convection" and "our aeronautical end-user defines the $36 \mathrm{dBZ}$ as moderate convection" [25]. The RDT polygons were thus validated against all radar reflectivity polygons that are greater or equal to $35 \mathrm{dBZ}$.

\section{Results}

Twenty-five cases were considered during the southern hemisphere spring and summer seasons. A few individual cases will be discussed first and then the statistical scores for all the cases will be shown.

\subsection{Case Study 1: 20 October 2012}

In Figure 3, the RDT without (a) and RDT with (b) lightning data added to the input data for 1700 UTC on 20 October 2012 are compared with the radar reflectivity image (c) for the same time. The RDT polygons outlined in red depicts all the storms in the growing phase, the purple polygons the storms in the mature phase, and the blue polygons the storms that are decaying. The black arrows associated with the RDT polygons point in the direction the storms are moving and the length of the arrows is related to the speed of the storms. The two RDT images are similar, except that a few additional storms were identified when lightning data were included. The green and yellow arrows show that these storms had higher reflectivities on the radar image. A mature storm was identified by RDT when lightning data was included in the software (indicated by blue arrow on Figure $3 b$ ) but was not identified by radar. In this case, the storm indicated by the blue arrow was next to another mature storm and the lightning associated with this storm also satisfied the criteria for the storm indicated by the blue arrow. As a result, the software forced the storm to be identified as a mature storm while in 
fact the radar did not identify any reflectivities above $35 \mathrm{dBZ}$. This is an example of a case where the RDT product might produce false alarms when identifying storms. Figure 3 also shows how the RDT product identifies the areas on the satellite image where significant storms are occurring by pointing out the areas of interest among all the non-convective clouds. The average of all the time steps for this day indicate that there was a $7 \%$ improvement in the POD (from 0.43 to 0.5 ), a $2 \%$ improvement in the FAR (from 0.19 to 0.17 ), and a $7 \%$ improvement in the HSS from 0.53 to 0.6 when lightning data is included in the RDT software.

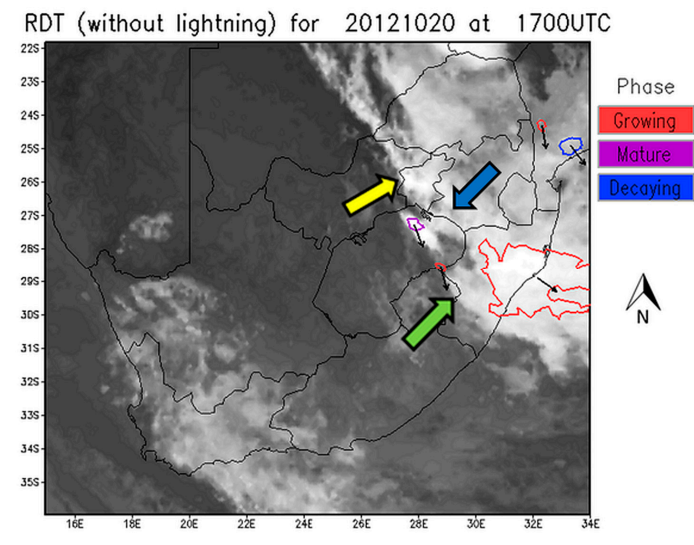

(a)

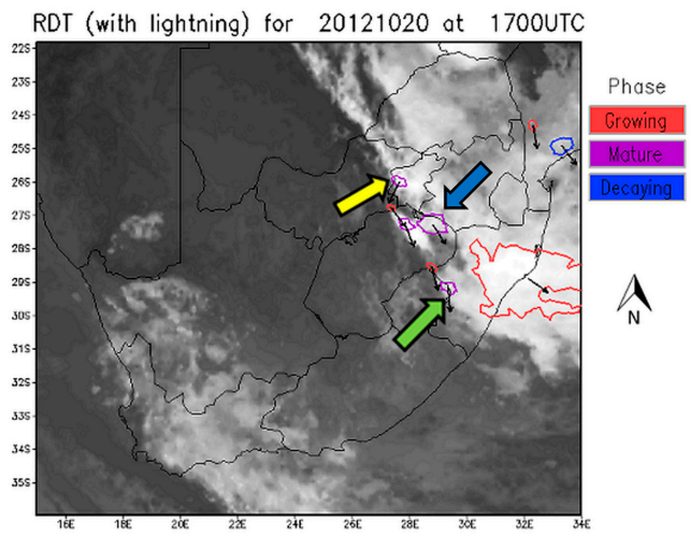

(b)

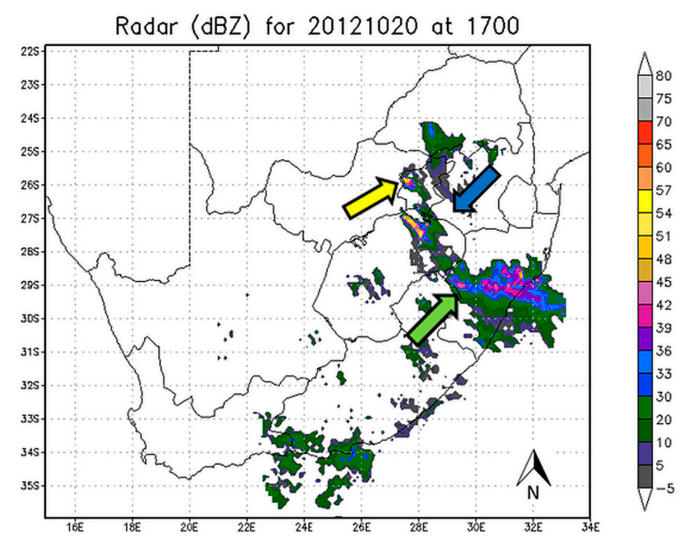

(c)

Figure 3. (a) RDT without lightning data; (b) RDT with lightning data; and (c) radar reflectivity in dBZ for 20 October 2012 at 1700 Coordinated Universal Time (UTC).

\subsection{Case Study 2: 21 March 2015}

Figure 4 shows the RDT without lightning (a), RDT with lightning included (b), and radar reflectivity (c) for 1300 UTC on 21 March 2015. Additional storms were again identified when lightning data were included in the input, and some of the phases of the storms changed. An intense storm ( $>50 \mathrm{dBZ}$ ) over the central parts of the country, as indicated by the yellow arrow, was identified when lightning data was included. The average of all time steps for this day shows that the POD score improved by $5 \%$ (from 0.76 to 0.81 ), the FAR increased slightly (from 0.062 to 0.067 ), and the HSS improved by $2 \%$ (from 0.83 to 0.85 ) when lightning data was added to the software. 


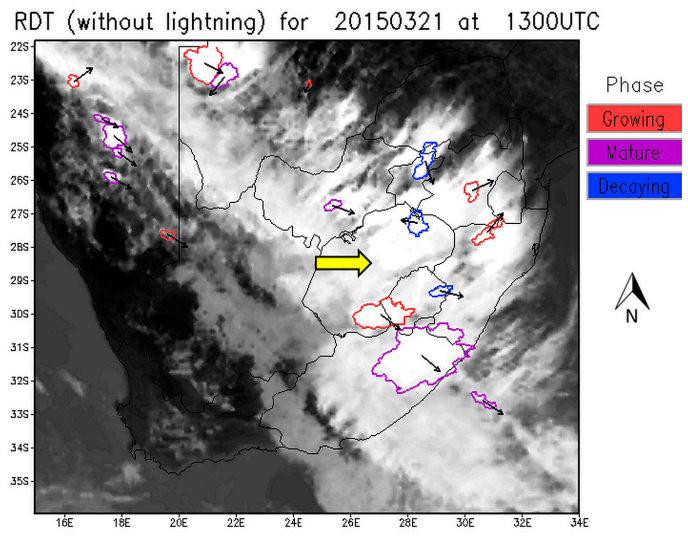

(a)

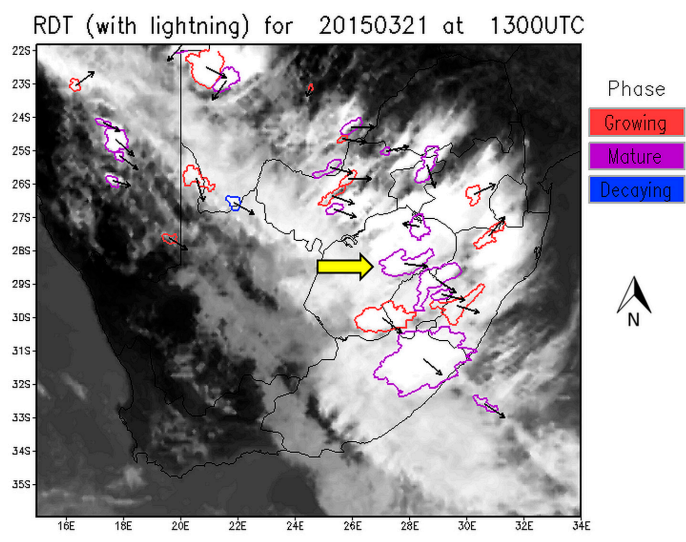

(b)

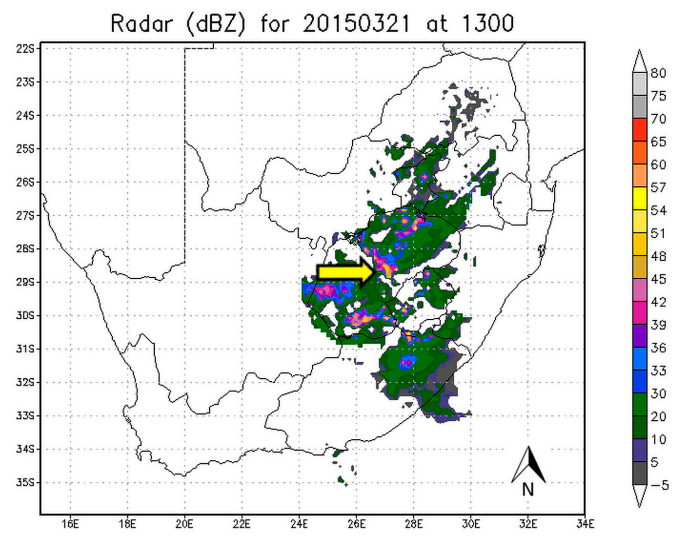

(c)

Figure 4. (a) RDT without lightning data; (b) RDT with lightning data; and (c) radar reflectivity in dBZ for 21 March 2015 at 1300 UTC.

\subsection{Case Study 3: 17 October 2012}

In Figure 5 the RDT without (a) and with (b) lightning data included into the input dataset at 1700 UTC on 17 October 2012 is shown. Radar reflectivity for the same time is also shown (c). A few additional storms were detected when lightning data were included (b). The storms indicated by the green and yellow arrows were not identified by RDT without lightning data included in the input, but were identified when lightning data were used as input. The radar image indicates that intense ( $>50 \mathrm{dBZ}$ ) storms did occur over these areas. Another difference between the RDT images is that the phase of some of the storms changed when lightning data were included. A few storms that were classified as decaying were classified as mature storms with the inclusion of lightning data. An average of all the time steps for this case indicates that the POD improved significantly by $21 \%$ from 0.57 to 0.78 when lightning data were added. The FAR was $2 \%$ better (0.07 compared to 0.09 ) and the HSS was $16 \%$ higher (0.84 compared to 0.68$)$.

\subsection{Results for All 25 Cases}

Figure 6 illustrates the HSS for all 25 cases for which the RDT was evaluated against radar. The dark green solid line shows the HSS when lightning was excluded from the software and the dotted light green line when lightning data was added as auxiliary input. The average HSS per day for all 25 days if lightning data were not included was 0.616 , while the HSS was 0.662 when lightning data were included, thus the HSS improved by $4.6 \%$. For 21 of the 25 cases the RDT validation showed improvement when lightning data were included, in three cases the validations were slightly worse and 
one case showed no change in the HSS. On day 24 (29 March 2015) and 25 (30 March 2015) (not shown), most thunderstorm activity occurred over the parts of South Africa which are not covered by radar and thus did not form part of the evaluation domain. Where radar coverage was available, very few thunderstorms occurred and the few RDT polygons were mostly associated with radar reflectivities less than $35 \mathrm{dBZ}$. This is also the end of the convective season in South Africa, and although convection still occurs, it is less intense compared to earlier in the season. As a result, the HSS scores were low. The inclusion of lightning data into the RDT did, however, improve the HSS for these two days by reclassifying the isolated storms identified by RDT (without the inclusion of lightning) that were associated with low reflectivities and lightning as non-convective storms. Cases 10-25 (used in this study) covered the period from 15 to 30 March 2015. These cases were selected to obtain some sort of running period in order to measure the performance of RDT on a daily basis, and not necessarily on days where significant thunderstorms occurred.

In Figure 6 the POD (bars) and FAR (lines) for the RDT product with (POD-light blue and FAR—light red) and without (POD—-dark blue and FAR—dark red) lightning data included as auxiliary data are compared for the 25 cases. On average, for the 25 cases, the POD was $6.6 \%$ better when lightning data were included and the FAR was slightly higher ( $0.1 \%)$. In 23 of the 25 cases, the POD improved, in case 18 the POD was marginally lower, and in case 22 the POD remained the same with and without lightning as input to the software. The FAR remained similar, showing a slight improvement in 13 of the cases and a small increase in 12 of the cases.

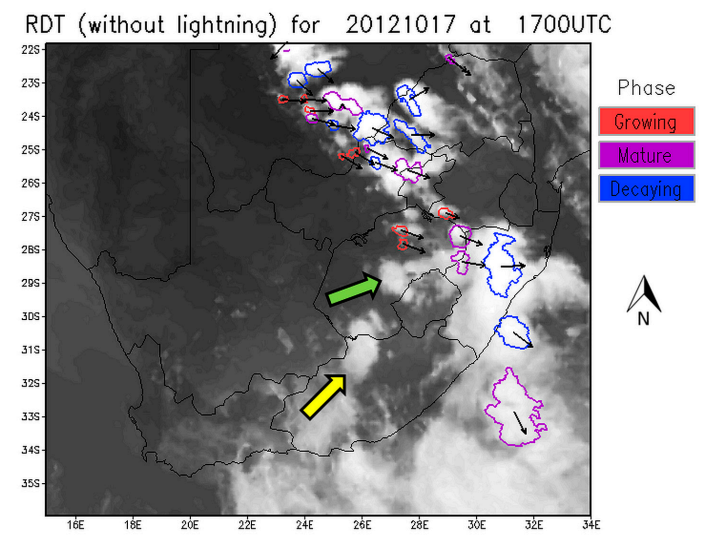

(a)

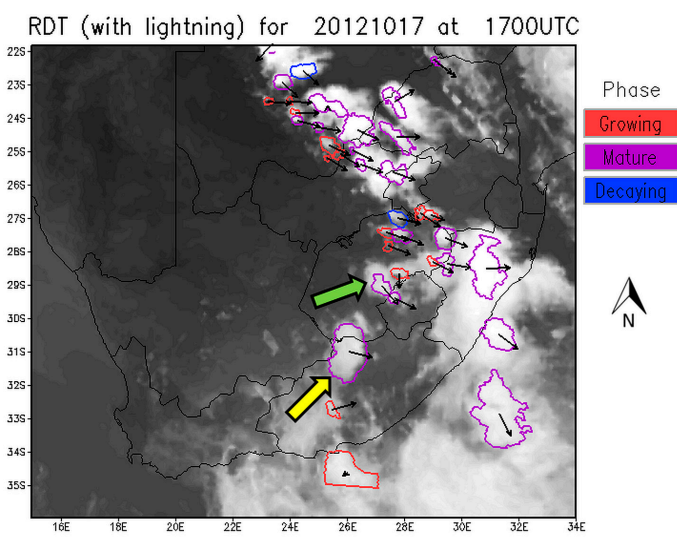

(b)

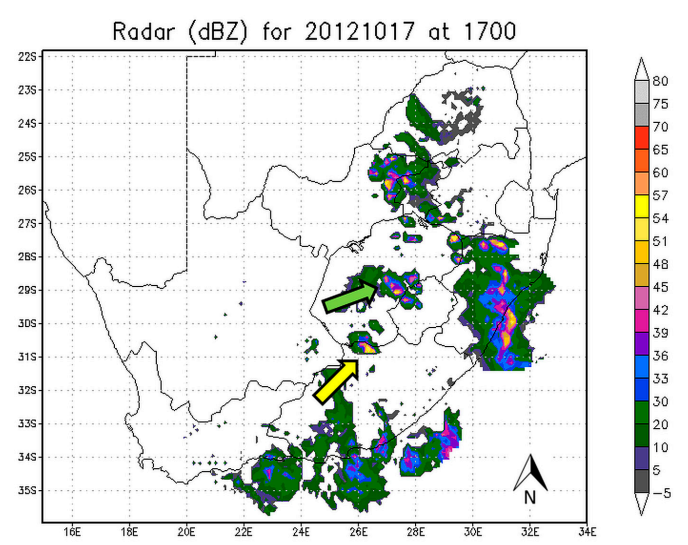

(c)

Figure 5. (a) RDT without lightning data; (b) RDT with lightning data; and (c) radar reflectivity in dBZ for 17 October 2012 at 1700 UTC. 


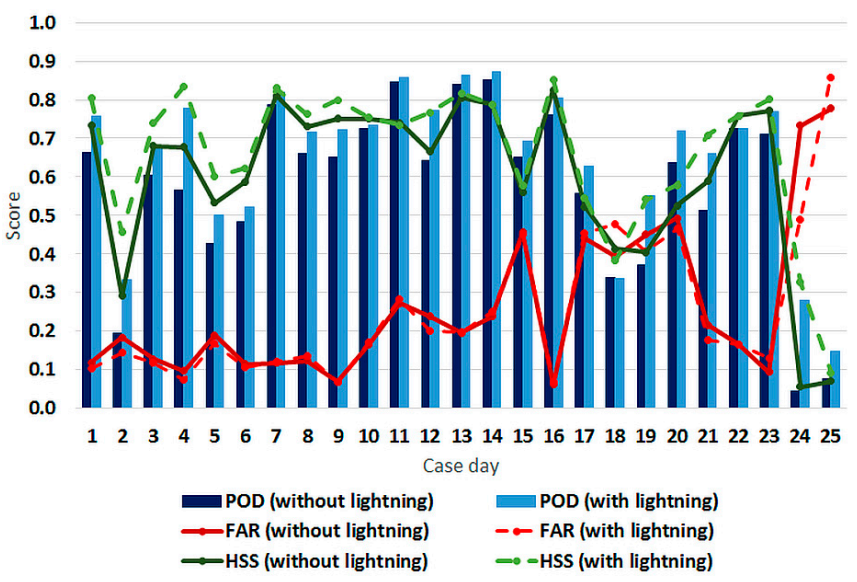

Figure 6. Probability of detection (POD), false alarm ratio (FAR), and Heidke skill score (HSS) for 25 cases without lightning data included (darker colors and solid lines) and with lightning data included (lighter colors and dashed lines).

It is also important to know if the RDT product performs better during certain times of the day. In Figure 7 the HSS, POD, and FAR for all 25 cases are compared for the different times of the day. The HSS (green lines) and POD (blue bars) show improvement to the RDT product for all time steps when lightning data were included in the input, except for the HSS at 1800. The FAR (red lines) is similar with/without lightning data included. From this graph, it is clear that the RDT validates well against radar for all relevant hours between 1100 and 1800 UTC, and shows an improvement when lightning data is added to the input dataset.

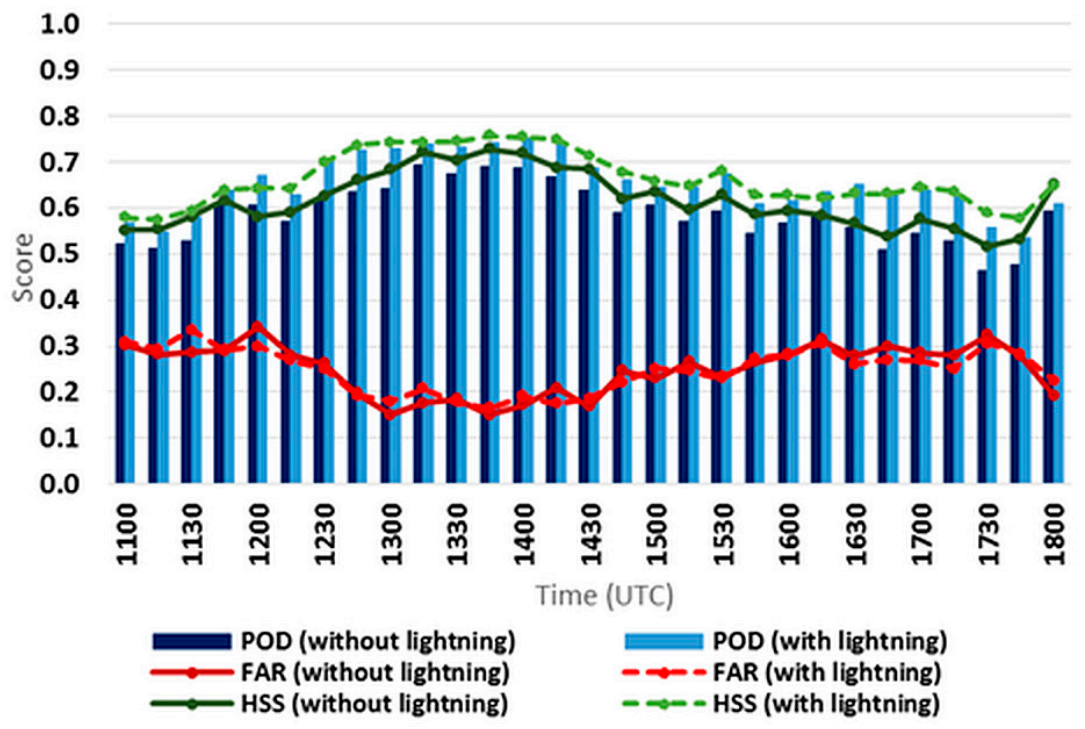

Figure 7. POD, FAR, and HSS during certain times of the day for the 25 cases without lightning data included (darker colors and solid lines) and with lightning data included (lighter colors and dashed lines).

Table 3 gives an overview of the average evaluation statistics calculated for all of the 25 cases and for all of the time steps between 1100 and 1800 UTC with and without lightning data added to the RDT software. These statistics show that the POD improved by $6.6 \%$, the FAR by $0.1 \%$, and the HSS by $4.6 \%$ with the addition of lightning data. The POFD remained similar, being $0.06 \%$ worse than before. 
Table 3. Average overall evaluation statistics for the RDT with and without lightning data added to the software.

\begin{tabular}{ccccc}
\hline Product & POD & POFD & FAR & HSS \\
\hline RDT Without Lightning & 0.5863 & 0.0149 & 0.2489 & 0.6160 \\
RDT With Lightning & 0.6524 & 0.0155 & 0.2479 & 0.6623 \\
\hline
\end{tabular}

POD: Probability of detection; POFD: Probability of false detection; FAR: False alarm ratio; HSS: Heidke skill score.

\subsection{The 3 March 2015 Case over Southern Africa}

The 3 March 2015 case forms part of a World Meteorological Organization (WMO) initiative of an eastern Africa Severe Weather Forecast Demonstration Project (SWFDP) that aims to provide severe weather forecasting and warning services over eastern Africa, which includes Lake Victoria [26]. Figure 8 shows the RDT product over the Lake Victoria area of southern Africa for 3 March 2015 at 1715 UTC (a) and 2000 UTC (b). Only satellite and NWP data were used as input in the software. On this day, a severe weather event that produced hail, heavy rainfall, and strong winds occurred south of the lake at Kahama in Tanzania [27]. The storm resulted in the deaths of 47 people, 5000 people were affected, and 634 houses were damaged [28]. The yellow arrows on Figure 8 indicate that at 1715 UTC the RDT already identified the development of rapidly developing storms south of the lake and by 2000 UTC a large mature storm was identified which was associated with hail, strong winds, and heavy rainfall. This example highlights the importance of such a product over data sparse regions for the nowcasting of thunderstorms where little observational networks exist. Currently there is no observational data available over this region to validate the products and one has to rely on reports of severe weather in order to demonstrate the usefulness of products such as the RDT over these regions.

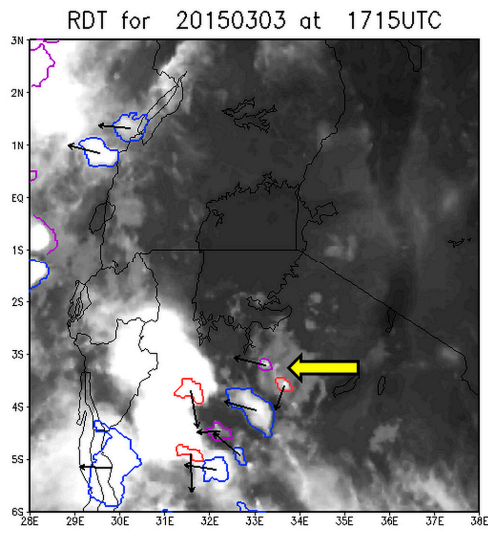

(a)

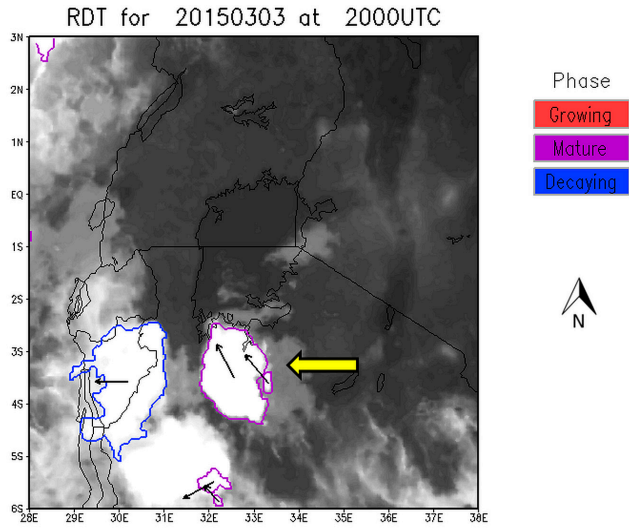

(b)

Figure 8. The RDT product over the Lake Victoria region in southern Africa at 1730 UTC (a) and 2000 UTC (b) on 3 March 2015.

\section{Discussion}

Twenty-five cases between September and March (convective season) were used to validate the RDT product that uses satellite and NWP data to identify and track more intense parts of thunderstorms, with and without lightning data included in the input dataset over South Africa. Statistical scores were calculated in an object-oriented way using radar reflectivity data greater than $35 \mathrm{dBZ}$ from the SAWS radar network as ground truth for each time step between 1100 and 1800 UTC. In the majority of the cases, the inclusion of lightning data was beneficial to the RDT product. Changes could be seen when images for individual times were compared. In many cases, the inclusion of lightning data into the software led to the identification of convective storms that were missed based 
on MSG data alone. These convective storms could have been missed due to the MSG signatures either not satisfying the criteria for being classified as a rapidly developing convective storm or the NWP data could have declassified these storms. With the inclusion of lightning data, these storms were reclassified and added to the output as rapidly developing convective storms. The inclusion of lightning data also resulted in some of the storm phases being adjusted based on the amount of lightning activity. For example, some of the storms were originally classified as being in the decaying phase, and the inclusion of lightning into the software reclassified these storms as mature storms based on the electrical activity.

On average, for these twenty-five cases and for all time steps, the POD improved by $6.6 \%(0.59$ to 0.65$)$, the HSS by $4.6 \%$ (0.62 to 0.66$)$, and the FAR by $0.1 \%(0.249$ to 0.248$)$ with the inclusion of lightning data. The POFD remained similar, but decreased in performance by $0.06 \%(0.0149$ to 0.0155$)$. For 21 of the 25 cases the HSS showed improvement when lightning data was included, in 23 of the 25 cases, the POD improved, the FAR remained similar, showing a marginal improvement in 13 of the cases and a marginal increase in 12 of the cases. The FAR did not change significantly when lightning data were included in the software since the aim of the lightning data is to force additional storms that are electrically active and were missed by satellite alone. Since none of the storm cells will be removed based on lightning data, an improvement in the FAR was not expected. The addition of a few electrically active cells that should be associated with reflectivity values exceeding $35 \mathrm{dBZ}$ could have improved the overall FAR scores slightly since a few more hits could have been included in the FAR calculations without the number of false alarm being affected. The results from this study, however, show that the FAR remains similar and shows that the inclusion of lightning data does not have a negative effect on the FAR. These statistical results show that the RDT product performs well even when lightning data is not added to the software. The addition of lightning data further enhances the product to give an even better representation of the rapidly developing thunderstorms.

The results obtained in this study compare well with the evaluation performed on the RDT by the developers over Europe. The evaluations performed over Europe did not include lightning as input into the processing software of the RDT since they evaluated the product against lightning data. They found that (using a time step approach) for low lightning activity (RDT associated with at least one lightning flash) the POD was 0.63, the POFD was 0.015, and the FAR was 0.2. For moderate lightning activity (RDT associated with at least five flashes) the POD was 0.65 , the POFD was 0.015 , and the FAR was 0.2 [7]. In this study, without (with) lightning added, the POD was 0.59 (0.65), the POFD was $0.015(0.016)$, and the FAR was 0.249 (0.248).

This work is specifically applicable for data sparse regions, where radar systems are not available. This includes areas over South Africa not covered by radar, as well as other southern African countries where very little observation networks are available. The MSG satellite covers the entire African continent and this makes MSG an ideal tool to monitor and track convection. By validating this product against the available radar systems in South Africa, it is evident that there is good agreement between the RDT polygons and radar reflectivity of more than $35 \mathrm{dBZ}$ even when lightning data is not used as an auxiliary dataset. This should provide the needed confidence that countries without radar systems can see the RDT product as a very good second option to radar data for convection and severe convection. This is evident from the 3 March 2015 example in Figure 8 over the Lake Victoria area, where the RDT identified rapidly developing storms at 1715 UTC, which developed into a severe thunderstorm with hail, strong winds, and heavy rainfall as can be seen at 2000 UTC.

The SAWS currently runs the NWC SAF software over the Southern African Developing Community (SADC) domain (African countries south of the equator), and makes the output of the RDT available on the Regional Specialized Meteorological Centre webpage [29]. This forms part of the WMO SWFDP that aims to improve the forecasting of severe weather over developing and least developed countries by means of forecast information on a website [2]. This website is accessible by all NMHS centers in the southern African SWFDP and provides valuable information to forecasters in 
data sparse countries. The RDT product is an extremely valuable tool over these countries and will be highly beneficial for the nowcasting of rapidly developing storms.

Future research options would include various aspects. Where lightning detection networks are available, these can be included into the input data or used as validation of the RDT (if lightning was not in the input dataset). When the next generation geostationary satellite for Europe and Africa is launched in 2019/20 by European Organisation for the Exploitation of Meteorological Satellites (EUMETSAT) in collaboration with the European Space Agency-the so-called Meteosat Third Generation (MTG) — a lightning imager will be on board, which will make lightning data for the entire African continent available. This will be a very rich source of data for this data sparse continent. Validation of how useful the RDT will be in this region with the MTG lightning data will have to be done, but should enhance the product over African countries.

The NWC SAF regularly upgrades the software suite and this is freeware available on the NWC SAF website [10]. A new version for the NWC SAF was released in 2016 and this should improve the RDT product. One of the improvements in the 2016 version of the RDT is the addition of forecast tracks and can provide a 15, 30, 45, and/or $60 \mathrm{~min}$ forecast of storms [30]. It will also be beneficial to evaluate the RDT product over South Africa for an extended period, preferably over the different seasons, but will depend on data availability and storage space. It would be recommended that as many countries as possible use satellite based nowcasting products, such as the RDT, to enhance nowcasting capabilities where other observations might be inadequate.

\section{Conclusions}

Radar systems are the ideal tools for the identification and tracking of convective storms. In many countries, however, these powerful tools are not available. The NWC SAF developed various satellite based tools which can address some of the nowcasting needs, of which the RDT is used for thunderstorm identification and tracking. The aim of this work was to test the effect of including lightning data as auxiliary dataset into the RDT product and to verify this against radar reflectivity of convective storms over South Africa. The results of twenty-five case studies over the South African domain showed that the inclusion of lightning data had a positive effect on the RDT product. However, even without the inclusion on lightning data the RDT product shows promise to provide information on possible severe or intense convective storms in regions that are not covered by radar systems. To our knowledge, South Africa is the only African country which is running the NWC SAF software operationally and which has performed an evaluation of the product over Africa against observations from radar systems and lightning sensors. The product is currently operationally available to all NMHS centers that form part of the southern African SWFDP (Botswana, Democratic Republic of the Congo, Lesotho, Madagascar, Malawi, Mauritius, Mozambique, Namibia, Seychelles, South Africa, Swaziland, Tanzania, Zambia, and Zimbabwe) and is a valuable tool for these data sparse countries that will assist with the nowcasting of thunderstorms. This product could also benefit the aviation industry for planning at the terminal as well the en-route environment.

Acknowledgments: The authors would like to thank the Water Research Commission (WRC) for funding this research. This work forms part of the WRC project entitled: Optimising the use of updated and additional products from the Nowcasting Satellite Application Facility.

Author Contributions: Morné Gijben and Estelle de Coning conceived and designed the experiments; performed the experiments; analyzed the data; contributed reagents/materials/analysis tools; wrote the paper.

Conflicts of Interest: The authors declare no conflict of interest. The funding sponsors had no role in the design of the study; in the collection, analyses, or interpretation of data; in the writing of the manuscript, and in the decision to publish the results.

\section{References}

1. World Meteorological Organization. Public Weather Services (PWS)-Nowcasting. Available online: http:/ / www.wmo.int/pages/prog/amp/pwsp/Nowcasting.htm (accessed on 16 March 2017). 
2. De Coning, E. Satellite Applications for Very Short-Range Weather Forecasting Systems in Southern African Developing Countries. In Recent Advances in Satellite Research and Development, 1st ed.; Gardiner, S., Olsen, K.P., Eds.; Nova Science Publishers: New York, NY, USA, 2013; Volume 1, pp. 67-92.

3. EUMETSAT, MSG Level 1.5 Image Data Format Description: EUM/MSG/ICD/105. Available online: http://www.eumetsat.int/website/wcm/idc/idcplg?IdcService=GET_FILE\&dDocName=PDF_TEN_05105_ MSG_IMG_DATA\&RevisionSelectionMethod=LatestReleased\&Rendition=Web (accessed on 16 March 2017).

4. De, C.E. Optimizing satellite-based precipitation estimation for nowcasting of rainfall and flash flood events over the South African Domain. Remote Sens. 2013, 5, 5702-5724.

5. Satellite Application Facilities. Available online: http://www.eumetsat.int/website/home/Satellites/ GroundSegment/Safs/index.html (accessed on 17 January 2017).

6. Météo-France. Algorithm Theoretical Basis Document for "Rapid Development Thunderstorms" (RDT-PGE11 v3.0); SAF/NWC/CDOP2/MFT/SCI/ATBD/11; Nowcasting Satellite Application Facility: Madrid, Spain, 2013.

7. Météo-France. Validation Report for "Rapid Development Thunderstorms" (RDT-PGE11 v3.0); SAF/NWC/ CDOP2/MFT/SCI/VR/11; Nowcasting Satellite Application Facility: Madrid, Spain, 2013.

8. Sieglaff, J.M.; Hartung, D.C.; Feltz, W.F.; Cronce, L.M. A satellite-based convective cloud object tracking and multipurpose data fusion tool for application to developing convection. J. Atmos. Ocean. Technol. 2013, 30, 510-525. [CrossRef]

9. Zinner, T.; Forster, C.; de Coning, E.; Betz, H.D. Validation of the Meteosat storm detection and nowcasting system Cb-TRAM with lightning network data-Europe and South Africa. Atmos. Meas. Tech. 2013, 6, 1567-1583. [CrossRef]

10. NWC SAF. Available online: http:/ / www.nwcsaf.org/HD/MainNS.jsp (accessed on 18 January 2017).

11. Landman, S.; Engelbrecht, F.A.; Engelbrecht, C.J.; Dyson, L.L.; Landman, W.A. A short-range weather prediction system for South Africa based on a multi-model approach. Water SA 2012, 38, 765-773. [CrossRef]

12. De Coning, E.; Gijben, M.; Maseko, B.; van Hemert, L. Using satellite data to identify and track intense thunderstorms in south and southern Africa. SAJS 2015, 111. [CrossRef]

13. Gijben, M. The lightning climatology of South Africa. SAJS 2012, 108, 44-53. [CrossRef]

14. Price, C.G. Lightning applications in weather and climate research. Surv. Geophys. 2013, 34, 755-767. [CrossRef]

15. Agencia Estatal de Meteorología; GMV Aerospace and Defence S.A.U.; Météo-France; Swedish Meteorological and Hydrological Institute; Zentralanstalt für Meteorologie und Geodynamik. Interface Control Document for the External and Internal Interfaces of the SAF NWC/MSG; SAF/NWC/CDOP2/INM/ SW/ICD/1; Nowcasting Satellite Application Facility: Madrid, Spain, 2013.

16. De Coning, E.; Koenig, M.; Olivier, J. The combined instability index: A new very-short range convection forecasting technique for southern Africa. Meteorol. Appl. 2010, 18, 421-439. [CrossRef]

17. Agencia Estatal de Meteorología; Météo-France; Swedish Meteorological and Hydrological Institute; Zentralanstalt für Meteorologie und Geodynamik. Software User's Manual for the SAFNWC/MSG Application; SAF/NWC/CDOP2/INM/MGT/SUM; Nowcasting Satellite Application Facility: Madrid, Spain, 2013.

18. Ebert, E.E. Fuzzy verification of high resolution gridded forecasts: A review and proposed framework. Meteorol. Appl. 2008, 15, 51-64. [CrossRef]

19. Gilleland, E. SpatialVx, R Package Version 0.6. Available online: http://cran.r-project.org/web/packages / SpatialVx/SpatialVx.pdf (accessed on 17 January 2017).

20. R Core Team. R: A Language and Environment for Statistical Computing; R Foundation for Statistical Computing: Vienna, Austria, 2015.

21. Wilks, D.S. Statistical Methods in the Atmospheric Sciences, 1st ed.; Academic Press: San Diego, CA, USA, 1995; p. 467.

22. Storm Identification. Available online: http://www.rap.ucar.edu/projects/titan/home/storm_identification. php (accessed on 17 January 2017).

23. Pierce, C.; Seed, A.; Ballard, S.; Simonin, D.; Li, Z. Nowcasting. In Doppler Radar Observation-Weather Radar, Wind Profiler, Ionospheric Radar, and Other Applications, 1st ed.; Bech, J., Chau, J.L., Eds.; InTech: Rijeka, Croatia, 2012; Volume 1, pp. 97-142.

24. Dixon, M.; Wiener, G. TITAN: Thunderstorm Identification, Tracking Analysis and Nowcasting-A radar-based methodology. J. Atmos. Ocean. Technol. 1993, 10, 785-797. [CrossRef] 
25. Moisselin, J.M.; (Météo-France, Toulouse, France); De, C.E.; (South African Weather Service, Pretoria, South Africa). Personal communication, 2016.

26. World Meteorological Organization. Satellite Products in Support of the SWFDP for the Lake Victoria Basin Region; CGMS-39 WMO-WP-21; Coordination Group for Meteorological Satellites: Darmstadt, Germany, 2011.

27. Goodman, S.J.; Virts, K.S.; Case, J.L. Nowcasting high impact weather for the Lake Victoria basin: Initial study of lightning forecasts and their validation. In Proceedings of the 8th Conference on the Meteorological Applications of Lightning Data, Seattle, WA, USA, 22-26 January 2017.

28. Tanzania: Hail Storms-Mar 2015. Available online: http://reliefweb.int/disaster/st-2015-000019-tza (accessed on 24 January 2017).

29. Regional Specialised Meteorological Centre (RSMC) Pretoria. Available online: http:/ / rsmc.weathersa.co. za/login.php (accessed on 24 January 2017).

30. Météo-France. User Manual for the Convection Product Processors of the NWC/GEO; NWC/CDOP2/GEO/MFT/ SCI/UM/Convection; Nowcasting Satellite Application Facility: Madrid, Spain, 2016.

(C) 2017 by the authors. Licensee MDPI, Basel, Switzerland. This article is an open access article distributed under the terms and conditions of the Creative Commons Attribution (CC BY) license (http:/ / creativecommons.org/licenses/by/4.0/). 